\section{SOME OBSERVATIONS ON STAMMERING AND ITS TREATMENT. ${ }^{2}$}

By ROBERT A. WORTHINGTON, M.B., B.C. CANTAB., M.R.C.S. ENG.,

HOUSE PHYSICIAN AT THE LONDON HOSPITAT.

THE explanations of this condition which have from time to time been proposed are so numerous and varied as to make it appear probable that the truth lies somewhere buried in the pile. Indeed, the literature of the subject is vast, but, as Kussmaul wittily puts it, most of the treatises have about as much value as the current pamphlets on balneology, so slight are the foundations in scientific proof of the opirions expressed. Among the minority of really enlightening papers published in recent years the chapter on Stammering in Wyllie's classical treatise on the "Disorders of Speech" ${ }_{2}$ has probably had the most influence in forming opinion in this country. I propose in the present paper to take up the subject at the point to which Wyllie has brought it and having pointed out wherein his analysis is incomplete, I shall endearour to give the complete explanation. Independent clinical evidence will then be adduced in support of this explanation. Finally, the consequent indications for treatment will be briefly discussed and incidentally a certain important property of speech-namely, rhythm-will be experimentally investigated.

It will be well to begin with a definition. This is the more necessary since some confusion has arisen through different interpretations of the terms "stammer" and "stutter"; a confusion which has been increased by the erroneous translation of the German "stammeln." "Stammeln" has, in fact, nothing to do with the condition known in English as "stammering," which is the translation of "stottern." The best definition of stammering which I have come across is that of Guillaume ${ }^{3}$ and may be translated as follows :-

We shall define stammering as a fault of speech, of irregularly intermittent type, principally characterised by the following two symptoms-(1) a spasmodic arrest before some syllable or other, such arrest taking place more particularly at the beginning of phrases (2) a spasmodic repetition of the same syllable again and again. To these two symptoms add certain spasmodic movements, appearing often at the very instant of the difficulty in speech, in the muscles the face and in divers parts ot the body quite unconnected with (hend and speech (head, arms, legs). Add to this a laboured tone of voice, as though the speaker were out of breath. Finally, let us add an abnormal secretion of saliva-ine grande superabondance de pituite, in the words of the ancients. This done, we have grouped together in a few lines the essential phenomena of stammering. If now we further emphasise two acts-namely, that on the one hand stammerers do not stammer in singing, and on the other that stammering is rare among women, we shall have a characteristic picture which, it appears be difficult to confound with any other defect of speech.

The second characteristic symptom described in the above definition-the spasmodic repetition of an initial syllableis that variety of stammering which is known in this country as "stuttering." It is not, however, a common symptom; in fact, not nearly so common as is generally supposed and in the majority of cases only occurs occasionally, if at all. The common forms of stammering may all be included under the heading "spasmodic arrest of utterance," different varieties of which we shall presently distinguish.

Turning now to Wyllie's analysis of the phenomena as above defined it may be stated briefly as follows: Speech is the result of the coördinated action of two mechanisms$(a)$ the rocal mechanism, consisting of the larynx and respiratory apparatus, whereby the voice is produced; and (b) the oral mechanism, the duty of which is to modify the exit of the voice in such a way as to produce words. (Note.I use the term mechanism throughout this paper as including both the muscular machine and its controlling nervous tract.)

Stammering is due to a functional disturbance the exact point of origin of which in the nervous tract is unknown but the result of which is a delay or want of promptitude in the production of the vocal element in speech. Owing to this delay the efforts of the patient to speak are

1 This paper is based on a graduation thesis read by the author in the Cniversity of Cambridge.

Wyllie: The Disorders of Speech, London, 1894.

${ }^{3}$ Guillaume : Article "Bégaiement," Dictionnaire Encyclopédique res Sejeaces Médicales, 1868 diverted into extra and wrong channels and result in irregular and spasmodic contractions of the muscles concerned in the oral mechanism and where facial contortions, movements of the head, arms, or body occur they are simply to be regarded as instances of a further overflow of energy. "That the doctrine is true," says Wyllie, "can be shown by many familiar proofs." He confines himself to one, and this is the more to be regretted as it is the only proof which I have so far come across. One, however, would be sufficient if complete. The argument appears to be as follows. Stammerers do not stammer when they sing. In singing the attention is particularly directed to the vccal element, which is relatively exaggerated, often at the expense of the articulatory element. Hence, stammering begins with defective vocalisation. Of the universal exemption from stammering while singing there is no question. And how far this argument is to be regarded as conclusive proof, how far merely as a probable explanation I do not intend to discuss. I propose to accept the conclusion as true and to make it the starting-point of a further analysis. I do this the more readily because, as far as my experience of the disorder has gone, I have come across nothing which seriously threatens this hypothesis. A stammerer myself, I have carefully examined my own sensations, particularly when not stammering severely (i.e. when the primary delay is not completely masked by excessive overflow), and they have only tended further to convince me. Furthermore, I may cite what has long been the experience of "stammer doctors" that gymnastic exercise of the oral mechanism alone has practically no profitable effect; whereas this is not the case if the gymnastics be applied to the vocal mechanism as I shall have occasion to show later.

In order to demonstrate the relation between the vocal and articulatory elements in each individual letter Wyllie constructed a physiological alphabet. In this the letters are divided into vowels and consonants. The consonants are subdivided into (1) voiceless oral $(p, f, s, t, k, h) ;(2)$ voiced oral $(b, x, v, \approx, d, l, r, g, y)$; and (3) voiced nasal resonants $(m, n, n g)$. Further, the consonants may be divided into the two characteristic types of explosives $(p, b, d, \& c$.$) ,$ and fricatives $(f, s, h, \& c$. $)$. In the enunciation of a voiceless explosive, as $p$ for instance, the voice is not thrown in until just after the lips have opened and the current of air has begun to pass out. If, on the other hand, the vocalisation is begun at the very instant of the parting of the lips, synchronously with the explosion of the air, the $p$ becomes $b$, a voiced explosive. There is a similar distinction between voiced and voiceless fricatives. Vowels are, of course, voiced throughout.

We may divide the common form of stammering into two main varieties :-

1. A complete arrest (" silent stick"-Wyllie) before some initial letter. This form occurs in nearly every case and is most common on the explosives. According to the hypothesis we have adopted the check is due to a delay in throwing in the vocal element on or just after the explosion.

2. An indefinite prolongation of an initial consonant. This occurs at fricatives $(f, l, s, \& c$.$) and nasal resonants,$ and is not so constant a feature as the first. In the case of the voiceless fricatives the difficulty may at once be ascribed to a delay in the vocal mechanism. But if it be a voiced fricative or a nasal resonant which is thus prolonged the explanation is not so obvious. Wyllie explains it thus : In the voiced fricatives and nasal resonants the stammerer produces the letter voicelessly, or with a feeble and inter mittent voice, and dwells upon it indefinitely. The voice is not thrown into it boldly, as it ought to be, and the speaker therefore feels that the proper sound has not been produced. There is also a further principle which must be recognised and which goes to explain occasional spasms in articulation not directly referable to vocal delay-namely, the development of secondary habits. In long-standing cases the nervous channels of overflow become worn very smooth and any attempt at speech may, from habit, produce delay or spasm in the oral mechanism. It is interesting to note that after the vocal mechanism is once brought even partially under conscious control it takes but very slight effort of the

4 As bearing on the mental condition of the stammerer in this connexion may be cited the common observation that stammerers will accept no compromise. They will, for example, allow no one else to say an obvious word for them or accept it as said, but will persist in their own futile efforts. 
will to prevent the continuance of such secondary habits, and as a rule they require no direct attention.

I have not included "stuttering" among the varieties of the common form of stammering because I believe it to be uncommon. The explanation, however, on Wyllie's hypothesis would appear to be that the stammerer produces the first half of the syllable feebly and then his voice fails altogether. He at once starts again but again his vocalisation is abortive and so he continues the repetition indefinitely.

I would now draw the reader's attention to the point when it appears to me that Wyllie's explanation is inadequate. Although be includes both the respiratory and laryngeal mechanisms in his definition of the vocal mechanism he appears to assume tbroughout his paper that the delay arises primarily in the laryngeal element and, indeed, he not infrequently uses the terms "vocal " and "laryngeal" as if they were synonymous. But we know that some letters are partly produced by the respiratory mechanism alone, with an open larynx ("voiceless" explosives and fricatives). Yet in stammering of the first variety (the "silent stick") the check occurs at the very beginning of such letters. And although this form of stammer is more common on explosives it is by no means infrequent on fricatives, the purely respiratory and voiceless character of which is perhaps more obvious. Thus, I have known persons who would come to a complete standstill before an $h$. Here, then, the delay occurs before there is any demand for voice, and to ascribe the spasm to delayed vocalisation is to put the effect before the cause. The indication, however, of this apparent anomaly is evident. It is to inquire into the relative responsibility of the respiratory and laryngeal mecbanisms for vocal delay.

Tabulating the ccördinated mechanisms of speech thus :-

A, Mechanism of $\{$ B, Oral mechanism

speech $\{\mathrm{C}$, vocal mechanism

(D, Laryngeal mechanism.

E, Respiratory mechanism

We have already seen that a delay in $\mathrm{A}$ is to be put down to a delay arising primarily in $\mathrm{C}$. It will not then be unreasonable to suppose that the delay in $\mathrm{C}$ may be itself due primarily to a delay in the action of either $D$ or $E$ separately. That the laryngeal mechanism is at fault has been argued by some on the ground that stammerers co not stammer when they whisper. The larynx being freely open during whispering and the cords out of action, it is supposed that speech is then carried out solely by the respiratory and oral mechanisms, and is unimpaired. Now this argument is false for two reasons. First, stammerers are by no means universally exempt when whispering. Thus, in the notes on 26 cases $I$ find (1) in six cases there is no information on the point; (2) in eight cases there is the definite statement that they do not stammer when whispering; and (3) whereas 12 cases did stammer on whispering, though not so frequently as in ordinary speech. The apparent amelioration during whispered speech is, I think, partly to be explained by the custom of speaking in this manner to intimates only in circumstances that are favourable to stammerers. The second reason is that the vocal cords are not entirely out of action during whispering. This was shown by Brucke and confirmed by Czermak. The sound in whispering is a fricative noise made by the air in passing between partially approximated cords. The distinction between voiced and voiceless letter remains unaltered during whispering except in degree.

Let us. then, now proceed to see how far the phenomena of stammering could be accounted for on the hypothesis that the primary delay lies in the respiratory mechanism. A stammer of the first variety can be completely explained on the supposition that the delay is primarily of the breath, but not on the supposition that it is of the larynx, for the latter would not account for arrest at the very beginning of any voiceless consonant, yet such an arrest is common. In the case, however, of the voiceless fricatives and a stammer of the first variety-e.g., a prolonged $f$ or $s$-it would appear that the delay can be explained only on the assumption of a primary laryngeal sluggishness. It will, however, be racalled that in explaining this form of stammer in voiced fricatives on Wyllie's hypothesis we recognise the feebleness of vocalisation as the probable cause. Now feebleness of vocalisation is due to feebleness of the air blast. Hence, having accepted this explanation we are making no further assumption if we regard dwelling on voiceless fricatives as due also to feebleness of air blast. Thus the two main varieties of stammering are completely accounted for by the fact that in the first the breath is altogether at a standstill and in the second it is driven out feebly and ineffectually. If now we imagine the blast to be intermittent our stammering will take on the third and rarer form-namely, stuttering.

In order to inquire into the occurrences in the respiratory mechanism during speech, normal or otherwise, I had recourse to the pneumograph. Now in the pronunciation of a consonant there is a mechanical check to the breath due to the approximation of the lips or the tongue and palate in one of the so-called stop positions. This check is com. municated to the thoracic wall and may be observed on the pneumographic tracing. It is more pronounced if the con. sonant be an explosive, less if it be a fricative; and it would seem reasonable to suppose that this mechanical check may act as a stimulus to the nervous delay, for it must be remembered that this delay is an active process and represents an exaltation of the inspiratory over the expiratory muscular mechanism. With regard to the vowels, I find there are two ways of initiating them when not preceded by a consonant. In the first the sound is begun perfectly smoothly (I do not mean aspirated). In the second the beginning is slightly explosive, giving the vowel a peculiarly incisive start. Unless the latter be much exaggerated the difference between the two methods is not marked and is only to be distinguished by careful listening. Now I can feel myself that a vowel begun. in the second manner would lend itself to stammering, whereas the first method of beginning I cannot imagine as presenting a difficulty. In ordinary speecb, I believe, it is usual to employ the second way in the case of vowels standing at the beginning of phrases-that is, to begin them in the incisive or slightly explosive manner-and it is only on such initiatory vowels that I have myself noticed a difficulty.

If the vocal cords be watched with a laryngoscope while a vowel sound is produced they are seen to behave as follows. In the first, or smooth method, the cords move up at once exactly into the position required for the note, leaving a narrow slit between them. In the second case the cords move up, meet in the middle, press against each other, and then open again into the position required for the note. In this way a consonantal sound, formed in the larynx itself, precedes the vowel. (We might term this a fourth stop

Fig. 1.

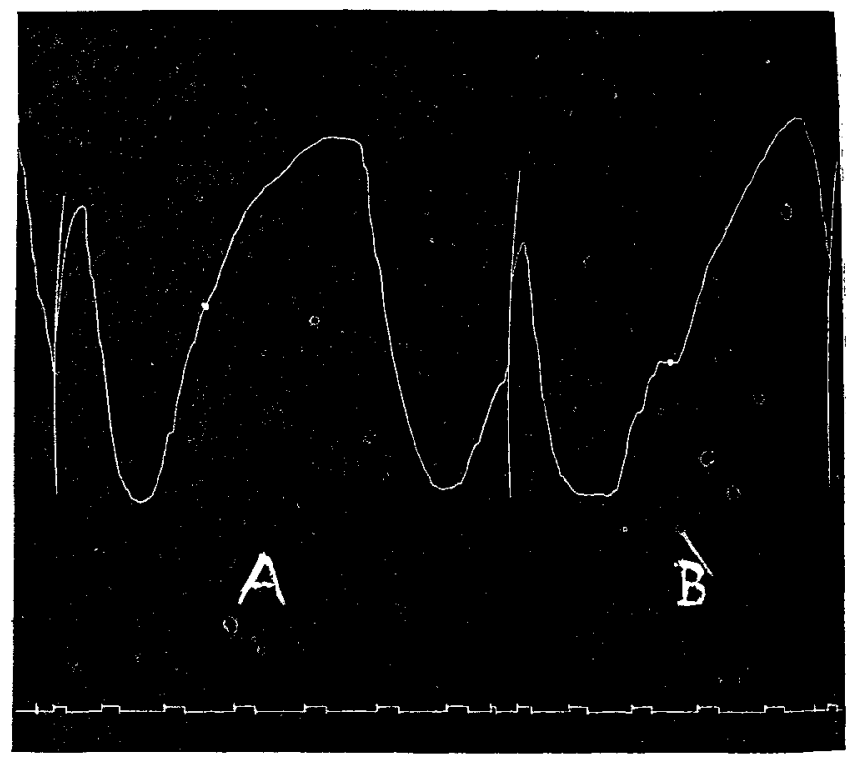

$\Delta$, Vowel begun in the smooth manner. $B_{2}$ Vowel begun in the explosive manner. The tracings read from left to right. The up-stroke represents expiration. The small dot indicat es the moment at which the vowel was begun. This was determined by beginning on the beat of a metronome, wh' se tracing is seen below the respiratory curres. (The heart beat.)

position.) Further, it is to be noted that the effect on a tracing of the respiratory movements is exactly similar to that produced by a consonant.

If a tracing be taken of the abdominal movements by a pneumograph round the waist, for example, and the vowel $a$ (as in car) be sung, but be brok en in the middle by a $d$ thus, $a-d a$; then, at the moment of saying the $d$ there is a slight pause in the movement of the abdominal wall. If 
now, in place of saying the first $a$ the breath be allowed to escape quietly and then at a certain point the vowel $a$ be begun, we see no pause on the respiratory tracing, provided the beginning is "smooth"; if it is of the explosive variety there is a definite check, exactly as with an explosive consonant. Two such tracings are here reproduced. ${ }^{5}$ (Fig. 1.) Now in stammering on a vowel the glottis can be felt to close tightly, just as the lips are tightly pressed together in stammering on a labial, and since we have been led to regard the labial spasm as secondary to a primary vocal delay we may, I think, not unreasonably regard the spasm of the cords as secondary to a primary respiratory delay.

In the majority of cases of stammering the order of diffculty is-(1) powels; (2) fricatives; and (3) explosives, in an ascending scale. And in treating such an occasional stick at the explosives of ten remains long after the fricatives have ceased to give trouble. I have put vowels lowest in the scale of difficulty, as I believe that to be usually the case. Bat, as might be anticipated $f_{1}$ om our previous observations, they are by no means always easy to stammerers and, indeed, in some cases present extreme difficulty. It is possible that this depends upon whether the speaker is naturally inclined to give them their explosive character or to begin them in the smooth manner with no preceding laryngeal closure. Consider now for a moment what probably occurs as the stammering babit is gradually developed in childhood. We may suppose that to begin with the child only stammers when the respiratory current is completely interrupted, as before an explosive. Later, as channels of overflow become smoother and secondary habits established, slight lagging of the breath is sufficient to produce a stammer and induce secondary delay in the laryngeal mechanism. Then the child begins to stammer on fricatives. Under treatment the troubles disappear in the reverse order to that in wbich they came. The relation which we have endeavoured to establish between the order of difficulty and the respiratory origin of the trouble receives indirect confirmation from the following exceptional case which I had the opportunity of examining. This was a small boy with a very severe stammer under the care of Mrs. Behnke, whose work in connexion with stammering and roice culture generally is so well known. Having arranged a pneumograph round his waist (he had already had some training in abdominal breathing) so as to record his respiratory movements I asked the patient to repeat some sentences. At the beginning of each phrase there was a long period of absolute silence during which his lips and the lower part of his face underwent writhing movements. During this period, however, the breathing did not cease; it be zame somewhat irregular and besitating but the patient continued to breathe in and out, apparently through his nose. Now this is a very unusual form of stammering. As a rule the breath is held till the word is at length enunciated. Sometimes it is held so long that the patient goes blue in the face. Here, then, surely was a case in which the delay could not lie primarily in the respiratory mechanism. And the point I wish to emphasise is that in this case the common order of difficulty was reversed; the voiced fricatives and vowels gave him most trouble and the explosives least. It is possible that the trouble had been primarily respiratory, but that the laryngeal centres had developed secondarily such great irritability that they now constituted what was virtually a primary centre of disturbance and had indeed become the more "explosive" of the two. It would appear, then, that the assumption of a primary respiratory delay goes very far towards explaining both the order of events and their immediate origin in the common form of stammering. There are, moreover, farther reasons for directing the attention to the respiratory mechanism in stammerers.

In 1891, three years before the publication of Wyllie's book, there appeared a monograph which, attacking the subject from a rather different point of view, is no less important. This is a reprint of a lecture given by the late Emil Behnke at the Central London Throat, Nose, and Ear Hispital. ${ }^{6}$ In this lecture Behnke expressed the view that in the majority of cases the respiratory mechanism is that which is primarily at fault. His reasons for this statement were founded on practical experiments in treatment. He

5 I cannot find that the respiratory phenomena during speech have hitherto been investigated with the pneumograph. That with which the tracings referred to in this paper were taken I constructed on the principle of "Brodie's bellows" and it proved very suitable for the purpose.

${ }^{6}$ Behnke: On Stammering, London, 1891. cited the enormous benefit derived from "diaphragmatic drill," or consciously controlled abdominal breathing. Since Mr. Behnke's death the treatment of stammering has been carried out along very similar lines by Mrs. Behnke. I have had the opportunity of seeing many of her cases at different periods during treatment, and I have become thoroughly convinced of the great practical value of directing the attention primarily to the respiratory mechanism. At my request Mrs. Behnke very kindly furnished me with notes on a considerable number of cases. ${ }^{7}$ When I asked for information she had for some time kept careful records of the breathing capacity, chest measurements, stature, and age of her patients, and she very kindly undertook to make systematic inquiries on many other points, including previous illness, local disorders, \& $s$. In the event I obtained (1) more or less detailed notes on 27 cases, 18 of which are male and nine female; (2) records of the age, stature, breathing capacity, and chest measurements of 66 cases (50 males, 16 females). One of the most striking things about the cases of which I have detailed notes is the high proportion of those who had suffered, or were suffering at the time they came for treatment, from morbid conditions in the upper respiratory passages, the nose and pharynx. Thus I find that out of 27 cases no less than 14 have a definite history of adenoids, enlarged tonsils, or some nasal obstruction. That is to say, over 50 per cent. were so affected, and possibly a larger percentage, as in some case 3 no definite information on the point was forthcoming. The cases of obstruction are made up as follows: (1) adenoids; (2) adenoids and chronic tonsillitis; ( 3 ) adenoids (as a child); (4) deflected septum and nasal obstraction; (5) chronic post-nasal inflammation, which had led to otitis media and deafness; (6) adenoids; (7) enlarged tonsils and deflected septum; (8) adenoids, enlarged tonsils; (9) adenoids, enlarged tonsils ; (10) enlarged tonsils ; (11) broken nose and deflected septum (since childhood), nasal polypi found on operation (12) adenoids; (13) adenoids; and (14) adenoids and enlarged tonsils. In addition there are one case of otitis media of unrecorded origin and one a photograph of whom as a child suggests adenoids and who remembered having been taught to breathe through his nose at about the age of 12 years. Now the influence of chronic inflammatory and hypertrophic conditions of the nose and pharynx on the shape of the chest and on the respiratory function in general bas long been recognised, and in practically every one of the above 27 cases it is recorded that the breathing was of the " high chest," as distinct from the "abdominal." variety. Further, an examination of the numerical data for 66 cases points to the fact that the breathing capacity of stammerers as a class is low.

Our knowledge of the breathing or vital capacity (Foster's "extreme differential capacity"-complemental + tidal + supplemental air) is chiefly derived from the work of Hutchinson. ${ }^{8}$ Although he made a magnificent series of observations (over 2000) he unfortunately published no record of the individual observations. His tables contain only the arithmetic means (average) of observations for different ages, statures, \&s. Thus we have no means of determining such important constants as the standard deviations, the probable error of the mean, \&c. Further, modern statistical theory has shown that the arithmetic mean is usually not the best expression for the most characteristic value of a variate. Amongst the reports of the Anthropometric Committee of the British Association is a table constructed by Roberts from material collected by himself and Beddoe. Here again he gives averages only, and no record of the individual observations was published. However, as these appeared to be the best data available, I took them for comparison with the observations in stammerers. And in order that the results might be comparable I dealt with the latter in a similar way. The comparison shows a very marked inferiority in the vital capacity of stammerers of all ages to that of normal people. For the actual statistics I may refer the reader to the London Hospital Gazette for January, 1905," where the observations will be found arranged in tabular form and compared for different ages and statures in the two sexes. It will be sufficient to cite here one example only.

7 I should like to take this opportunity of recording my great indebtedness to Mrs. Behnle during this inquiry; her practical experience was as invaluable in any question

8 Hutchinson: Transactions of the Royal Medical and Chirurgical Society, 1846. 
A comparison was instituted between stammering boys under 15 years of age and the boys of the Industrial School at $S$ winton. The returns from this school were pronounced by the Anthropometric Committee to be "a model of what such returns should be." The report also pointed out that "boys of this, the industrial class, are nearly seven inches shorter in stature and $24 \frac{3}{4}$ pounds lighter in weight than the first or standard class" (children of the upper and professional classes); and between stature and vital capacity Hutchinson's observations pointed to a high degree of correlation. In spite of these facts we find a very marked inferiority in the breathing capacity of the stammerers. Thus, for example, the mean vital capacity of the stammerers of 12 and 13 years of age (nine cases) is 88 and 109 cubic inches respectively, whereas in the industrial school children it is 166 cubic inches at both these ages. On the other hand, the mean stature of the stammerers is 57.5 and 60.9 inches for the two ages, and of the industrial children 52.5 and 54.0 inches, an average of six inches less. The stammerers being drawn from the upper and professional classes the last figure agrees closely with that given by the Anthropometric Committee. The statistics for adults were no less striking and a consideration of all the figures $I$ think justifies the statement that there is evidence in favour of a real inferiority in the vital capacity of stammerers. The evidence is strong but not conclusive. Strong because (1) the mean difference between stammerers and normal people is large; and (2) the individual observations with very few exceptions all tend in the same direction. It is not conclusive, for that the observations compared were made by different persons with different instruments alone introduces many possible errors of unknown magnitude. To what, then, do these apparent deficiencies in the respiratory organs of stammerers point? Considering how close is the sympathy between any organ and the nervous centre controlling it and how morbid conditions of the one may be reflected in the other as, at any rate, some impairment in function, the inference suggested is that any want of promptitude in the action of the vocal mechanism as a whole probably has its starting-point in the respiratory half of that mechanism. And I would here point the argument by reference to an analogous disease.

In Allbutt's "System of Medicine" stammering is put into the same group as the occupation neuroses, of which writer's cramp is the best known, and with this a certain similarity of condition is pointed out. How close that similarity is, is not, I think, generally realised. Vivian Poore, writing on writer's cramp, has the following passage : "Now, directly an act which should be automatic begins to demand our attention for its execution the difficulties of executing such an act are increased a hundredfold. Fear of failure, especially before others, is ever present to the mind, and it would seem as if a certain proportion of that mental stimulus which ought to animate the muscles suffered what we have called emotional diversion and thereby caused increased muscular impotence. In every case of writer's cramp that the author has seen there has been an emotional factor. Those who have had the most obvious physical cause for their troubles have complained that their troubles are worst in the presence of others and especially when they have been called upon for official signatures before official witnesses." Substitute " stammering" for " writer's cramp" and the above passage may still stand almost unchanged. In writer's cramp there is the onset of spasm in the muscles of the hand on attempting to write, altbough those muscles may be perfectly effective for other actions. Thus Osler quotes the case of a distinguished gynæcologist who suffered from the disease in an aggravated form and yet retained all the finer movements necessary for his operating practice. A stammer of the speech, on the other hand, is accompanied by, and, as I have attempted to show, starts with, a spasm of the respiratory muscles. The spasmodic arrest of the diaphragm on the "silent stick" may be readily seen with the $x$ rays (Mrs. Behnke). Yet apply the respiratory muscles to anything but ordinary speech, to singing or to quiet breathing, and there is no tendency to spasm. Further, it has been observed by Gowers and Poore that the most fruitful cause of writer's cramp is a cramped and defective method of writing-writing from the wrist rather than the elbow or shoulder, and it is supposed that, given a neurotic subject, this defective and laboured method of using the hand in writing reacts morbidly upon the nervous centres presiding over the action and produces a condition which has been well described as "irritable weakness." It is impossible to resist the suggestion of a very similar etiology in the case of stammering-namely, that defective conditions in the respiratory passages in the child, leading to an improper and laboured mode of breathing, especially during speech, when longer expiratory intervals are required, produce a similar irritable weakness in the centre for speech, a condition naturally spreading from that part of the centre particularly connected with the respiratory function.

Before passing to a consideration of treatment the con. clusions at which we have so far arrived may be briefly summarised. They are as follows: That, if it be granted that stammering is due to a delay or want of promptitude in the action of the vocal mechanism, the phenomena are com. pletely explained if we regard the delay as arising primarily in the respiratory half of this mechanism; that the phenomena are not completely explained if the delay be located as primarily in the action of the laryngeal mechanism, and only secondarily in the respiratory mechanism; and that there is evidence which points to an inferiority in the respiratory function in stammerers, independently suggesting that this may be the primary seat of the trouble.

\section{ON TREATMENT.}

My own experience being rather that of being treated than of treating I cannot pretend to dogmatise on this subject. All I shall do is to state in general terms the procedure which would appear to be the logical outcome of the view as to the nature of stammering, which I have endeavoured to justify in the previous part of this paper.

Following Kussmaul, ${ }^{10}$ we may conveniently consider treatment under two heads, prophylactic and educative.

1. Prophylactio treatment will aim at inducing in the body generally, and in the organs concerned in speech in particular, as sound and vigorous a condition as possible, in order that the patient may the more readily respond to subsequent educative treatment. Stammering being essentially a neurosis it is hardly necessary to empbasise the im. portance of seeking for, and removing if possible, any causes of chronic nervous irritation or depression. An ample suffi. oiency of fresh air and exercise should be secured. Too little work is probably as bad for stammerers as overwork, as it lessens that power of mental control which is conservative of energy and which delimits the area of brain required for any action. The respiratory tract will especially demand our most careful attention. As a rule, it will be found that the respiration is of the thoracic rather than the abdominal type. Now Keith ${ }^{12}$ has shown that the descent of the diaphragm is the most efficient way of aerating the lungs, and that smaller movements of this wall are required for the respiration of a given quantity of air, than of any other wall of the thoracic cavity. $\mathrm{He}$ has shown further that it is by the expansion of the diaphragmatic wall that the apices of the lungs are aerated, thus correlating the incidence of pulmonary tuberculosis in the two sexes at different ages with the assumption or otherwise of the so-called abdominal type of breathing. Hence there is every reason to encourage "diaphragmatic" or "abdominal" breathing and I think that the patient should be definitely taught to make use of this type of breathing. The effect of such training on the vital capacity of stammerers was well brought out in the records of Mrs. Behnke's 66 cases, the mean percentage increase being $31 \cdot 3$ after periods of treatment varying from a few weeks to several months. On turning the attention next to a point a lit:tle higher up the respiratory tract-the laryn $\mathrm{x}$ - it may be found that the patient's voice is of interior quality. It appears that adult stammerers not infrequently speak in a rather high-pitched thin voice. The patient should then be given exercises which will enable him to place his voice in the proper register and at a lower pitch. Finally, the throat and nose must be examined, any obstruction should be removed, and the patient trained to breathe through his nose. Ideally, in. spiration should always take place through the nose, even while, as in speech, the mouth is open.

2. Educative treatment.- Having thus attended generally to the health of the patient and the condition of his vocal organs the next thing to do is to train those organs to proper and coördinate action in speech. The exercises which have

Kussmaul: Disturbances of Speech, in Ziemssen's Cyclopædia of the Practice of Medicine.

11 Keith: Hunterian Lecture on the Anatomy of Glénard's Disease, The LanceT, 1903, March 7tb, p. f3l: also London Hospital Gazette, January, 1904, in a discussion on "Why does Phthisis Attack the Apex 
been devised for this purpose fall naturally into two classes : 1. Exercises in which the attention of the patient is directed towards the result produced, the method of producing it being thus indirectly controlled. 2. Fxercise in which the attention is directed to the actual movements of some part of the mechanism of speech so as to predetermine the result produced. For example, if a passage be read aloud slowly and with exaggerated clearness and precision of enunciation it would form an exercise of the first class in articulation. If, on the other hand, the reader has acquired a knowledge of the exact position that the tongue and lips should occupy for the pronunciation of each letter, and in reading the passage be were consciously to put his articulatory apparatus through the requisite movements, then the exercise would be one of the second class. The value of exercises of this second class, provided they are of that part of the mechanism of speech which is the seat of the primary disturbance, is very great. Both classes lessen the frequency with which disturbances tend to arise. But the second class gradually gives the patient the power to avert an impending disturbance by deliberately controlling that part of the mechanism which is primarily at fault.

In the common form of stammering due, as I have endeavoured to show, to a respiratory delay the exercises we should naturally seek are such as will especially control the respiratory function. If the patient practises reading in a loud full voice, dwelling on the vowel sound in each syllable, and touching off the consonants as lightly as possible, he will be giving the respiratory function a good exercise of the first class. A full and loud voice implies a powerful expiratory blast; to dwell on the vowel sounds determines the blast being well sustained, and lightly to articulate the consonants causes the interruptions to the blast to be short (see Fig. 2). If next the patient directs his attention while he

FIC: 2.
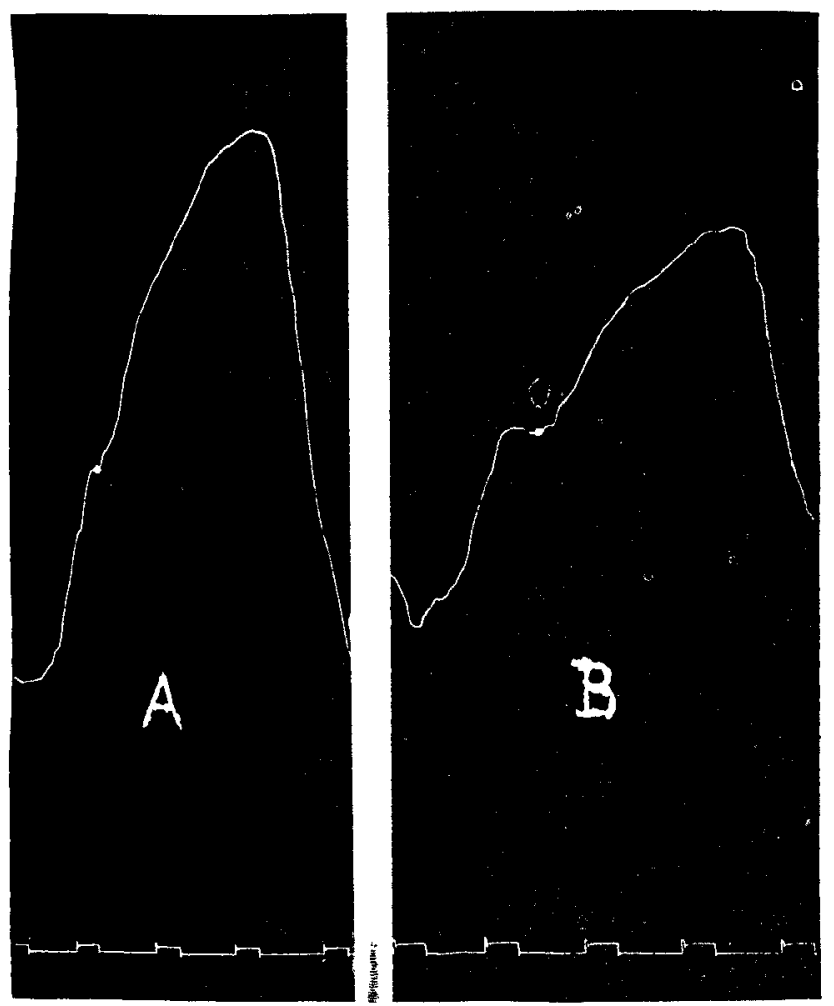

Showing the effect of (A) a consonant "lightly" articulated, and $(B)$ the same firmly or " heavily" articulated, on the respiratory tracing. Each tracing represents the vowel sound $a h$ broken in the middle by a $d$-thus, a-da. In ordinary speech the interruptions are as a rule very slightoften less than that in $A$.

is saying words in this fashion to the accompanying thoracic and abdominal movements so as to become actively conscious of them the exercise will be converted into one of the second class for the respiratory mechanism and will thereby, as I believe, possess additional value.

Now there is a quality of speech which is solely determined by a proper and orderly management of the breath-namely, rhythm. It has long been observed that stammerers read verse with greater facility than prose and advantage has been taken of this fact in their treatment. Colombat, ${ }^{12}$

12 Colombat: Traité de tous les Vices de la Parole et en particulier le Bégaiement, Paris, 1843.
Merkel, ${ }^{13}$ and in recent years Mrs. Behnke, ${ }^{11}$ have taught the advantage of emphasising the natural rhythm of all speech. The observance of rhythm implies the raising of the intensity of the sound in the syllables on which the accent falls and the observance of a certain time relation between those syllables. This rise in intensity is solely dependent on a more powerful blast of air at the moment. Hence, if we exercise the stammerer in reading with an exaggerated rhythm we shall indirectly exercise the

FIG. 3.

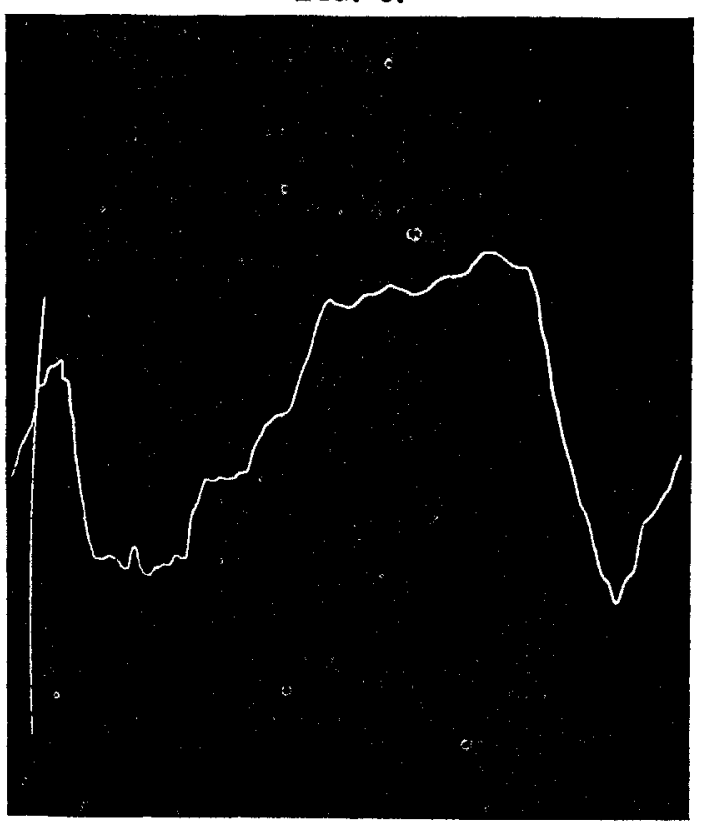

A pneumographic tracing taken while saying the sentence, "No less than fifteen men had passed the Conjoint." It was said fairly rapidly in an ordinary way, without particularly observing its rbythm.

FIG. 4.

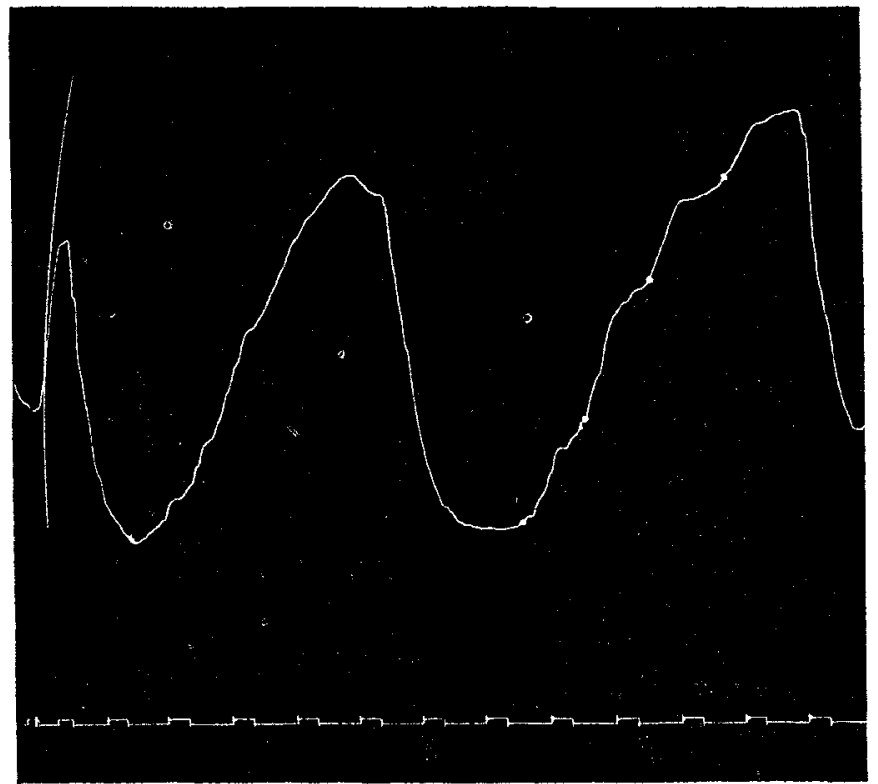

Experiment to show the effect on a respiratory tracing of alterations in the intensity of the voice, uninterrupted by consonarts, and the pitch refor tory part (up-stroke) of the first curve represents the vowe sound ah sung with (fairly) constant intensity and at a constant pitch. The secosa curve shows the effect of raising the intensity of the tone on the beats of a metrothe mall dots indicate approximately the points at which the ntensity was raised. It is to be noted that the pressure exerted by the respiratory muscles varies as the square of the velocity of the out-driven current of air, so long as the laryngeal aperture is constant. Hence the variations in pressure, which produce variations in the intensity of the voice, are proportional to the square of the amplitude of the accompanying waves in the pneumographic tracing. Thus very slight undulations in the tracing may be evidence of quite appreciable variations in the muscular activity.

13 Merkel : "Stammeln" und "Stottern," in Scbmidt's Encyklopädie der gesammi en Medicin; also Ph, siologie der Menschlichen Sprache, er gesammitent

Leipsic, 1866 it Mrs. Behnke : The Speaking Voice, Loncion. 
expiratory act in a series of augmentations and retardations (exercise of first class). Merkel, however, made the great mistake of saying that "during the entire expiratory interval (in speech) the respiratory muscular system should be kept at the sume degree of tension." A study of the pneumographic tracings of the respiratory movements during speech completely disproves this view, for in ordinary conversation certain syllables are always accentuated above others, ${ }^{1 \overline{5}}$ and these variations in intensity are all accompanied by variations in what Merkel termed the tension of the respiratory muscular system (-ee Fig. 3; also Fig. 4). The rhythm, however, in the example given (Fig. 3) is very irregular and, although typical of the conversation of most people, not such as we hear in the best speakers. Let the stammerer then, imitating the latter, adopt a rbythmical mode of speech and he will simplify the demands on his respiratory muscular system by reducing the variations in its rate of movement from an irregular to a regular seriesthat is, to a series which be subconsciously forecasts independently of the words and which is therefore less easily disturbed. The effect of an accentuated rhythm on the respiratory tracing is illustrated in Fig. 5.

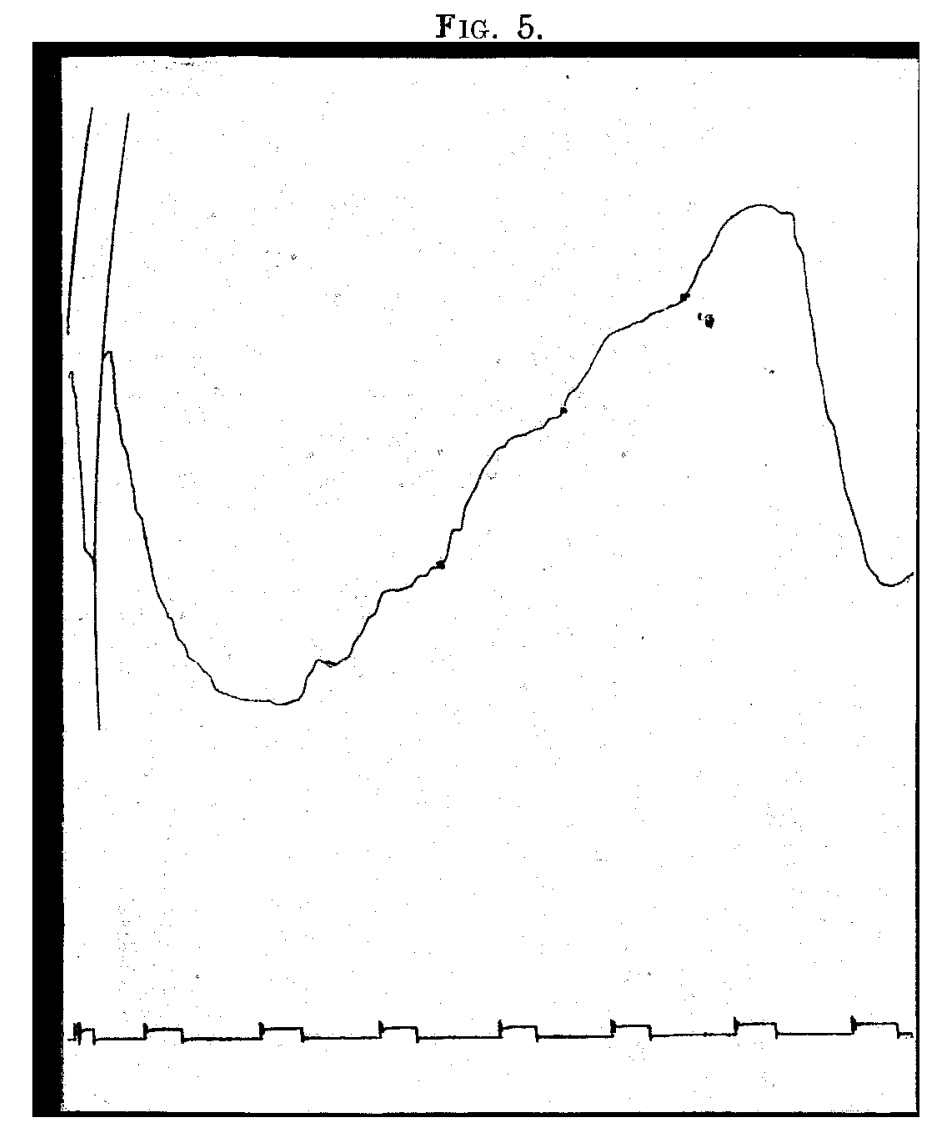

Pneumographic tracing of the sentence, "Every tone must be clear and distinct." spoken slowly and with the rhytumical syllables accentuated and slightlv prolonged. The beginning of each accentuated syllable is indicated by a small dot on the tracing.

After a little practice with a pneumograph on myself, observing both the tracing point and my own sensations simultaneously, I found that I very quickly became conscious of the finer variations in the rate of movement of the respiratory muscular system, and not until he has acquired or perfected this consciousness is the stammerer in a position to give his respiratory mechanism perfect exercises of the second class in the movements required in speech. My own pl in has been as follows: to take an elastic belt and to tie it moderately tight round the waist about midway between the umbilicas and sternum. In this way I found it easier to focus the attention on the abdominal and lower thorac:c movements. I then read aloud some lines which I knew well, accentuating the rhythm by a voluntary exaggeration of the expiratory movements, and with the attention so far as possible concentrated on these movements. Of all the many forms of exercise that I have tried I consider this to be the most efficient, having regard to the time expended in such exercise.

It is a pity that the public do not realise that there is a

If they are not, the roice, although it may vary in pitch, becomes monotonous and wearisome and the speaker himself quickly tires. Such appears to be the most fruitful cause of "parson's sore throat." sense in which the cure of stammering is probably never complete. A stammerer cured is not the same as a man who has never stammered. Without incessant watchfulness on his part his malady is certain to recur. The recognition of this would prevent much disappointment and misapprehension-misapprehension which too often arises from a belief that the secret of cure is some specific in the hands of this or that practitioner. The treatment of every case is essentially individual, and the experienced trainer takes advantage of any slight peculiarities which can be turned to account in establishing a habit of control. Nevertheless, we may perhaps be permitted to summarise the general principles as follows: 1 . Remove, as far as possible, any local physical inferiority in any of the organs concerned in speech. 2. Determine in what part of the mechanism the disturbance primarily arises and which of the phenomena are secondary. 3. Ignore the latter, but devise exercises of the second class for the former. 4. Endeavour to induce in the stammerer a constant habit of speech which shall itself be an exercise of the first class. Southsea.

\section{PHLEGMONOUS CHOLECYSTITIS.}

By G. A. WRIGHT, M.B. OxON., F.R O.S. ENG., PROFESSOR OF STSTEMATIC SURGERT, VICTORIA UNIVERSTTY OF MANCHESTER; SURGEON TO THE ROYAL INTIRMARY, MANCHESTER.

PhLegmonous cholecystitis may be defined as a severe form of acute inflammation of the gall-bladder going on to suppuration in the wall of the gall-bladder or even to local or general gangrene. Robson tells us that this-the "acute progressive empyema" of Courvoisier-was first described by Potain in 1882, but it will be found that Wilks and Moxon mention that acute idiopathic inflammation " with formation of pus in the wall or great infiltration of it with lymph or ulceration have been met with in fever and in cholera." Robson relates some cases in his book and another in his Hunterian lectures (1904) in which the condition was due to gall-stones impacted in the lower part of the common duct. Suppuration of the pancreatic ducts also occurred and the patient died on the fourteenth day. It is, however, admittedly rare and but little mention of it will be found in most of the larger text-books, though Rolleston gives a full acconnt of it. The fact that three cases of it have come under my observation in the last few years shows that it is not so rare as to be negligible. It is, moreover, practically certainly fatal from peritonitis with or without perforation or from toxæmia unless it is recognised and dealt with. Even after operation the mortality is exceedingly high.

Phlegmonous cholecystitis is somewhat difficult of diagnosis and liable to be mistaken for acute intestinal obstruction, acute pancreatitis, and acute appendicitis. In a case published by Hotchkiss and in one of my own the mischief was thought to be appendicular before operation. In Lane's case $^{1}$ acute obstruction of the large intestine was diagnosed, and indeed existed, as the result of pressure from effused lymph. In a case of Roswell Park ${ }^{2}$ a diagnosis of appendicitis was also made, but acute suppurative cholecystitis with gall-stones was found. This case recovered after operation. D. A. K. Steele ${ }^{3}$ relates a case which was treated by incision and died suddenly from pulmonary embolism on the eighth day and another in which a færal abscess formed with subsequent discbarge of gall-stones through the operation wound. Sheild, in $1895,{ }^{4}$ records a case of perforation, possibly from typhoid fever, and quotes Murchison on the subject. Richardson ${ }^{5}$ relates and comments upon nine cases of varying degrees of severity, only one or perhaps two being actually gangrenous. In the Transactions of the Philadelphia Academy of Medicine for May, 1904, G. Davis mentions a case of gangrene associated with calculus. A pericystic abscess existed and in spite of cholecystectomy the patient, a man, aged 70 years, became delirious and died after some weeks. ${ }^{6}$ Gibson reported a case to the New York Surgical Society of discharge of

1 The Lancet, Feb. 25th, 1893, p. 411.

2 Bacillus coli communis, Annals of Surgery, 1893. 3 Annals of Surzery, vol xli.

4 The LANCET, March 2nd, 1895, p. 534.

5 American Journal of the Medical Sciences, vol, exv. 6 Annals of Surgery, 1904. 